\section{Desprovincializar o desenvolvimento: enunciação subalterna e resistência nas bordas da acumulação capitalista na Amazônia}

\author{
Wendell Ficher Teixeira Assis \\ \& Anabelle Santos Lages*
}

Resumo: Para refletir sobre a continuidade dos processos de subalternização e expropriação de populações tradicionais e camponesas, o artigo se valerá de abordagens aglutinadas no paradigma modernidade-colonialidade. Tentar-se-á conectar a problemática teórica assim construída com o conhecimento empírico de lideranças indígenas sobre as modificações territoriais ocorridas na Região Amazônica durante os anos 2000, num movimento que permitirá questionar certos aspectos da realidade social, bem como fazer girar a espiral que conecta abstração conceitual e realidade concreta. Com esse intuito, a análise aqui empreendida lança mão de dois trabalhos de campo conduzidos em distintos espaços amazônicos; o primeiro levado a cabo na região oeste do Pará, que desde a última década tem sido o cenário de intensos conflitos entre as frentes de expansão econômica e as populações tradicionais; o segundo realizado na TI Raposa Serra do Sol, que representa um caso paradigmático, no qual estiveram em xeque o digladio entre racionalidades e modos diferentes de uso, significação e apropriação dos territórios.

Palavras-chave: colonialidade-modernidade, desenvolvimento, processos de subalternização, expropriação territorial, resistência.

\section{Introdução}

Recebido: 23.10 .15

Aprovado: 20.06 .16

\author{
* Wendell Ficher \\ Teixeira Assis \\ é doutor em \\ planejamento urbano \\ e regional, professor \\ adjunto do Instituto \\ de Ciências Sociais \\ da Universidade \\ Federal de Alagoas \\ e pesquisador do \\ Laboratório Estado, \\ Trabalho, Território \\ e Natureza do Ippur/ \\ UFRJ.<wwficher@ \\ yahoo.com.br>. \\ Anabelle Santos \\ Lages é doutora em \\ sociologia e bolsista \\ PNPD do Programa \\ de Pós-graduação \\ em Sociologia \\ da Universidade \\ Federal de Alagoas. \\ <anabellelages@ \\ yahoo.com.br>.
}

\begin{abstract}
Não esperem que eu me ponha a demonstrar que, em nosso meio, confunde-se barbaramente a civilização com as leis do desenvolvimento normal autêntico, a demonstrar que a civilização há muito já está condenada no próprio Ocidente e que ali é defendida apenas pelos proprietários a fim de salvarem o seu dinheiro.

Fiodor Dostoiévski, Notas de inverno sobre impressões de verão (redigido em 18621863).
\end{abstract}

A construção das hierarquias raciais, de gênero e de modos de apropriação dos recursos naturais pode ser vista como simultânea e contemporânea à constituição de uma divisão internacional do trabalho e do território, marcada por relações assimétricas entre economias cêntricas e periféricas. No contexto 
brasileiro, mediante a atuação do Estado e dos instrumentos de mercado, tem-se verificado a continuidade de um colonialismo interno (Gonzalez-Casanova, 2006) que coloca em marcha a expansão da acumulação capitalista em direção à fronteira agrícola, acarretando o deslocamento de populações tradicionais e camponesas que ancestralmente ocupam a região Amazônica. A despeito da força desses mecanismos de poder, que operam em múltiplas arenas, essas populações têm-se insurgido contra as formas de usurpação de seus territórios, ao mesmo tempo em que enunciam e praticam modos contra-hegemônicos de uso, apropriação e significação dos recursos naturais. Esses sujeitos, que historicamente têm sido subalternizados, questionam, portanto, o caráter provinciano da lógica de desenvolvimento que, mesmo se particular e limitada, apresenta-se como universal e englobante.

Para refletir sobre a historicidade e continuidade desses processos de subalternização e expropriação, o artigo se valerá das abordagens teóricas reunidas no paradigma modernidade-colonialidade. Tentar-se-á conectar a problemática teórica assim construída com o conhecimento empírico das modificações territoriais concretas ocorridas na região amazônica, num movimento que permitirá submeter à interrogação certos aspectos da realidade social, bem como fazer girar a espiral que conecta abstração conceitual e realidade empírica. Com esse intuito, a análise aqui empreendida lança mão de dois trabalhos de campo conduzidos em distintas zonas da Amazônia. O primeiro levado a cabo na região oeste do Pará, mais precisamente nos municípios de Santarém, Óbidos, Juruti e Oriximiná, que desde a última década tem sido o cenário de intensos conflitos entre as frentes de expansão econômica e as populações tradicionais; o segundo, realizado em Boa Vista (RR), com o objetivo de captar as percepções das lideranças indígenas da TI Raposa Serra do Sol, que representa um caso paradigmático, no qual estiveram em julgamento o digladio entre racionalidades e modos diferentes de uso, significação e apropriação do território.

O procedimento metodológico ancora-se na realização de entrevistas em profundidade que foram conduzidas com quatro lideranças indígenas Arapiuns e três Borari, durante o período de 21 maio a 14 de julho de 2012, nos municípios do oeste do Pará, além de duas entrevistas com lideranças Wapichana e Macuxi concretizadas em Boa Vista entre os dias 6 e 23 de julho de 2012. Para interpretação e compreensão do material coletado, utiliza-se a análise de discurso e de conteúdo (Orlandi, 1988; Maingueneau, 1997; Fairclough, 2001), buscando elucidar os diferentes argumentos e significados enunciados por esses sujeitos na tentativa de defesa e reconquista de seus territórios, bem como na crítica ao modelo unidimensional de desenvolvimento que lhes é impingido. A partir da junção entre uma abordagem teórica que sublinha o histórico de relações assimétricas e a manifestação concreta desses artifícios na contemporaneidade amazônica, espera-se demonstrar que 
mesmo submetidas a processos de subalternização, as populações camponesas, indígenas e ribeirinhas têm feito ressoar vozes que questionam, insurgem e propõem novas estratégias de desenvolvimento.

\section{Colonialidade-modernidade: implicações nos processos de acumulação capitalista}

Na perspectiva da colonialidade, as antigas hierarquias coloniais que foram agrupadas na relação europeu versus não europeu continuam arraigadas e enredadas na divisão internacional do trabalho e na acumulação do capital em escala global. No argumento de Mignolo (2003), a colonialidade permaneceu invisível sob a ideia de que o colonialismo seria um passo necessário em direção à modernidade e continua a ser invisível hoje, sob a imagem de que o colonialismo acabou e de que a modernidade é tudo o que existe. A construção de novas nações "independentes" representou, assim, simplesmente uma nova fase do sistema modernidade-colonialidade e não significou o fim das práticas colonialistas. Em outras palavras, a descolonização e a construção de nações tornou-se uma nova forma de articulação da colonialidade do poder nas Américas, na Ásia e na África (Mignolo, 2001).

Para Wallerstein (1979), os Estados periféricos, que hoje são oficialmente independentes e alinhados com discursos liberais, construíram ideologias de identidade nacional que produziram uma ilusão de independência e progresso econômico. Do mesmo modo, Grosfoguel (2006) argumenta que as múltiplas e heterogêneas estruturas globais, implantadas durante 450 anos, não se evaporaram juntamente com a descolonização jurídico-política da periferia. Com a descolonização, transitou-se de um período de colonialismo global para um período de colonialidade global, contudo manteve-se a mesma matriz colonial de poder. A colonialidade constitui, portanto, um dos elementos do padrão mundial de poder capitalista, que se fundamenta na imposição de uma classificação racial, étnica e civilizatória de toda a população do mundo (Quijano, 2000b). Como esclarecido, em outros termos, por Maldonado-Torres (2007):

Colonialidade não significa o mesmo que colonialismo. Colonialismo denota uma relação político-econômica, na qual a soberania de um povo reside no poder de outro povo ou nação, o que constitui tal nação como um império. Diferente dessa ideia, a colonialidade se refere a um padrão de poder que emerge como resultado do colonialismo moderno, mas que ao invés de estar limitado a uma relação formal de poder entre dois povos ou nações, melhor se refere à forma como o trabalho, o conhecimento, a autoridade e as relações intersubjetivas se articulam entre si através do mercado capitalista mundial [...] (Maldonado-Torres, 2007: 131). 
1. Para entender os desdobramentos desse processo na produção de conhecimento contemporânea, Khatibi (1997) trabalha com a noção de sociedades silenciadas, onde, é claro, há fala e escrita, mas essas não são ouvidas ou lidas na produção planetária de conhecimento guiada pelas sociedades silenciadoras ou desenvolvidas.
Na tentativa de entender as estratégias de poder subjacentes ao exercício da coIonialidade, Quijano (1997; 2000a) desenvolveu a ideia de colonialidade do poder como modelo de exercício da dominação especificamente moderno que interliga a formação racial, o controle do trabalho, o Estado e a produção de conhecimento. Em outras palavras, a colonialidade do poder é a classificação social da população mundial ancorada na ideia de raça, que tem origem no caráter colonial, mas já provou ser mais duradoura e estável que o colonialismo histórico, em cuja matriz foi estabelecida (Quijano, 2000a). O mesmo poderia ser dito do estabelecimento de relações sociais cujo modo operativo favorece a constituição de sujeitos subalternizados intra e interestatais. Guha (1997), em seu trabalho clássico Dominance wilthout hegemony, sustenta que subalternidade não é somente uma questão de subordinação de classe dentro de um país industrial, mas de subordinação de organizações sociais e históricas no interior de estruturas interestatais, como as que se estabeleceram entre Índia e Inglaterra. Para o autor indiano, o colonialismo britânico se caracterizou pelo exercício de uma dominação sem hegemonia, uma composição seriamente determinada pela dissolução dos elementos de persuasão e cooperação, que se ancorava na força despótica da superioridade ocidental para erigir uma dominação política que aniquila o surgimento do dissenso ou conflito. No tocante a esse aspecto, a colonialidade do poder não é uma entidade homogênea experimentada de maneira uniforme por distintos grupos subalternizados (Walsh, 2002). Portanto, é imperativo evitar a sedução das taxonomias essencialistas e enxergar o conceito de subalterno como relacional e relativo (que faz referência a sujeitos sociais heterogêneos - um sujeito pode ser subalterno em relação a outro e ao mesmo tempo dominante em relação a um terceiro).

Embora Dussel (2000) considere que o ego cogito cartesiano (1636) foi antecedido em mais de um século pelo ego conquiro (eu conquisto) hispano-lusitano, que impôs sua vontade de poder sobre os nativos das Américas, é inegável sublinhar a existência de vinculações entre as estruturas de produção do conhecimento e o bom andamento da empresa colonial. A filosofia se constituiu, desde o início, como instrumento de subalternização de formas de conhecimento que se situavam fora de suas fronteiras já disciplinadas (Mignolo, 2003). Para Garcés (2007), o conhecimento e as ciências sociais se foram construindo a serviço da empresa de dominação, conquista e controle da Europa sobre o mundo. De modo que, sem o desenvolvimento de um tipo de conhecimento útil dirigido a controlar todas as ordens da vida social, não teria sido possível o projeto de expansão capitalista. A coIonização inaugura, por conseguinte, uma nova episteme direcionada a legitimar a rapina, a escravização, o aniquilamento da diferença, a superioridade dos europeus e a expropriação dos territórios ${ }^{1}$. 
Essa matriz de pensamento - que se expressa por meio da colonialidade do poder - procurava e ainda procura encobrir o fato de que a Europa foi produzida a partir da exploração político-econômica do continente americano. Não há como desconsiderar as implicações históricas do estabelecimento desse padrão de poder, que se reflete na recíproca produção histórica da América e da Europa, como redes de dependência histórico-estrutural (Quijano, 2005). Entretanto, o caráter constitutivo da experiência colonial e da colonialidade não figura nas abordagens hegemônicas e eurocêntricas, e mesmo de intelectuais latinos, que desprezam a importância que as relações intercontinentais tiveram para a emergência do capitalismo. A esse respeito, Garcés (2007) sinaliza que a América Latina foi fabricada como algo deslocado e periférico em relação à modernidade, os intelectuais de nossos países assumiram tal deslocamento e se esforçaram para serem modernos, como se a modernidade fosse o ponto de chegada e não a justificação da colonialidade.

Como jamais fomos modernos (Latour, 1994), a colonialidade do poder abre uma porta analítica que desvela o lado mais obscuro da modernidade e clarifica o fato de nunca ter sido possível - nem poder vir a ser admissível - modernidade sem colonialidade. Como destaca Mignolo (2003), faz-se necessário realçar que a modernidade é um projeto que não poderá nunca ser completado, porque a modernidade não pode sê-lo sem colonialidade. Nessa direção, Escobar (2003) propõe a desnaturalização e a desuniversalização da ideia de modernidade como forma de romper com a colonização da realidade que é operada pelo discurso do desenvolvimento. Para tanto, elenca cinco distinções que particularizam o paradigma colonialidade-modernidade, bem como o diferencia da visão hegemônica, que conclama uma modernidade una, linear e unidirecional. A primeira consiste em localizar as origens da modernidade na conquista das Américas e na abertura do circuito comercial Atlântico, após 1492, diferindo da perspectiva dominante que situa o surgimento da modernidade no lluminismo europeu do final do século XVIII. A segunda é uma atenção persistente ao colonialismo e ao desenvolvimento do sistema mundial capitalista, como constitutivos da modernidade, isso inclui uma determinação de não ignorar a economia e suas formas de exploração. A terceira deriva da adoção de uma perspectiva planetária na explicação da modernidade, ao invés de uma visão que prima por a apresentar como fenômeno intraeuropeu. Já a quarta realça a dominação e o sujeição de outros povos mundo afora como sendo uma necessária dimensão da modernidade, sem desconhecer a consequente subalternização da cultura e do conhecimento daqueles povos que foram atirados à periferia pelo centro europeu. Por último, mas não menos importante, uma concepção do eurocentrismo como representação e forma de conhecimento hegemônico que constrói sua própria universalidade calcada numa abstrata superioridade. 
2. A hifenização da palavra pretende realçar os desafios de uma enunciação sub-alterna - que pode estar em situação inferior sub, mas é alterna e representa outra perspectiva. Busca-se clarificar a existência de discursos que, a partir da perspectiva hegemônica, são considerados subalternos e/ou inferiores, mas, que a despeito disso, representam a possibilidade de construção de um novo modelo civilizador que, partindo de uma ótica tida como sub, visa alternar o pensamento dominante.
Ao lançar luz sobre o lado obscuro da modernidade, o paradigma colonialidade-modernidade clarifica que os diferentes discursos históricos (evangelização, civilização, modernização, desenvolvimento e globalização) têm como ideário sustentar a concepção arbitrária de que há um padrão civilizatório que é simultaneamente superior e normal (Lander, 2000). No receituário clássico da modernidade, bem como nos desdobramentos hodiernos do capitalismo, duas alternativas infernais (Stengers \& Pignarre, 2005) têm sido infligidas aos povos subalternizados: uma decorre da completa aniquilação, outra da civilização imposta. Grosfoguel (2007) esboça um marcador temporal para esse processo de extermínio e sujeição das sociedades sub-alternas ${ }^{2}$ ao assinalar que nos últimos 513 anos do sistema mundo europeu/ euro-americano moderno/colonial capitalista fomos transitando do "cristianiza-te ou te mato", do século XVI, ao "civiliza-te ou te mato" do século XVIII e XIX, ao "desenvolva-te ou te mato" do século XX e, mais recentemente, ao "democratiza-te ou te mato" de princípios do século XXI.

Com base na elaboração teórica aqui sintetizada, pode-se indicar a perpetuação de significados que, formulados a partir de uma racionalidade hegemônica, aproximam o conceito de civilização das ideias de modernidade, tecnologia, espaço, progresso, conquista, desenvolvimento, velocidade e dinamismo, enquanto o conceito de cultura remeteria a noções tais como tradição, rusticidade, arraigo ao lugar, atraso, entrega, irracionalidade econômica, fixidez e monotonia. Nesse sentido, a próxima seção procurará realçar como populações subalternizadas por esse projeto unidimensional enunciam sentidos que rompem com essa hierarquização provinciana.

\section{Quando fala o subalterno: a diferença cultural como crítica ao desenvolvimento}

Para romper com esses pares dicotômicos que constroem a cultura como a expressão do atraso, Escobar (2005) argumenta em defesa do lugar como projeto dinâmico e não como sítio estanque fora do tempo. Da mesma forma, Massey (2000) desloca os sentidos reacionários das noções de lugar, apresentando-o como encontro entre os momentos experenciados localmente e as redes de relação e entendimentos sociais situadas em outros espaços. Já Dirlik (1997) aponta a existência de uma assimetria nos discursos da globalização, nos quais o global é igualado ao espaço do capital, da história e de sua agência, ao passo que o local e o lugar são enxergados como sinônimos de trabalho, tradição e fixidez. Essas visões críticas, que ressaltam os vínculos múltiplos entre identidade, lugar e poder, têm o mérito de evitar a naturalização de categorias, ao mesmo tempo em que problematizam a constituição de identidades essencializadas e, equivocamente, consideradas autênticas. 
A univocidade, linearidade e unidimensionalidade, que compõem o discurso e as razões da modernidade, aplacam e ressignificam práticas e sujeitos sociais, enquadrando-os em uma visão hegemônica e excludente de futuro e desenvolvimento. Para Castro-Gomez (2000) a modernidade representa uma máquina geradora de alteridades que, no entanto, em nome da razão e do humanismo, exclui de seu imaginário a hibridez, a multiplicidade, a ambiguidade e a contingência de formas concretas de vida, elaborando, assim, a imagem quimérica de um todo integrado e homogêneo. Entretanto, para Khatibi (2001), caminha-se nas sociedades subalternizadas para uma tomada de consciência da diferença cultural irredutível, que questiona a reprodução dos valores elaborados a partir de uma mirada estritamente econômica ancorada na percepção europeia ou estadunidense. Nesse quesito, o excerto disposto a seguir, extraído de entrevista realizada com uma liderança indígena Arapiuns, no oeste do Pará, apresenta as razões de uma voz dissonante que expõe as ameaças de expulsão de suas terras e questiona a unidimensionalidade do desenvolvimento:

Nós queremos continuar aqui, isso aqui é nosso. Esse território é nosso, a gente não caiu de paraquedas aqui, a gente não foi enviado para cá, a gente nasceu, se criou e queremos morrer dentro do que é nosso [...]. Eu quero, na nossa luta, conquistar uma maneira de nosso povo viver, porque sobreviver nós já sobrevivemos. A gente discute sempre com os colegas e com os parentes que a gente não é contra o desenvolvimento da Amazônia, mas nós queremos participar desse desenvolvimento. Nós não queremos que esse desenvolvimento seja construído dentro de um gabinete e seja simplesmente jogado para cima da gente, não, senta com a gente, a gente não é esse contra, existe tantas formas de se desenvolver a Amazônia sem ferir os direitos de quem mora e vive aqui dentro (entrevista com liderança indígena Arapiuns Z, Santarém (PA) 9 Jun. 2012).

Em resposta às lutas das comunidades tradicionais e populações camponesas ocorridas ao redor do mundo, visando ao reconhecimento de seus direitos, a atual organização global da economia tem logrado formular um discurso ilusório que conclama o respeito às diferenças culturais e a alteridade. Na visão de Castro-Gomez (2000), essa afirmação celebratória da diversidade, tão em voga no cenário contemporâneo, está longe de subverter a lógica do sistema; ao invés disso, pode estar contribuindo para consolidá-lo sobre novos pilares. Já para Maldonado-Torres (2010), esse novo dispositivo de poder, ancorado na constituição de sociedades que celebram o multiculturalismo, encobre um multirracismo ainda mais profundo, que apenas reconhece direitos à diferença quando as pessoas já estão bem domesticadas pelo capitalismo, pela economia de mercado e pelos ideais liberais de igualdade e liber- 
3. Em diálogo

com a ascensão e o fortalecimento daquilo que Hale (2002) tem chamado de multiculturalismo neoliberal, Walsh (2007) argumenta que 0 reconhecimento e a tolerância em relação aos outros, que o paradigma multicultural promete, não só mantém a permanência da iniquidade social, como deixa intacta a estrutura social e institucional que constrói, sustenta e reproduz a existência dessas iniquidades. dade. No atual jogo político-econômico do mundo colonial-moderno se reeditam, portanto, estratégias seculares de subordinação, donde, a partir de uma visão particular, se definem tanto o universal como as formas de aceitabilidade do diferente, ou melhor, se determinam quais diferenças devem ser aceitas. Não obstante, cabe considerar a possibilidade de que atores sub-alternos minem essa predestinação e forjem novas formas de reivindicação e exercício da diferença capazes não somente de extrapolar, como de questionar a contenção de demandas expressa pela ordem multiculturalista hegemônica ${ }^{3}$. Isso pode ser notado no trecho transcrito a seguir extraído de entrevista realizada com uma liderança indígena Arapiuns, que, na luta pelo reconhecimento étnico e pela demarcação de suas terras, tem enfrentado madeireiros, sojicultores e órgãos estatais que, reiteradamente, questionam a legitimidade do pleito indígena e procuram minar a reafirmação identitária do grupo:

\footnotetext{
Olha, eu não me reconheço indígena, eu sou indígena. Para mim, ser indígena não é estar de cocar na cabeça, estar pintado ou de colar no pescoço, para mim ser indígena tem que estar no sangue, tem que estar no coração. Indígena indígena, sem terra, sem território não é indígena, ele não vive, ele morre. Eu quero dizer para as pessoas que nos chamam de índios ressurgidos que nós não somos ressurgidos, nós somos resistentes, por resistir a milhares de anos de massacres. Eu não me considero um índio ressurgido, eu sou um indígena resistente (entrevista com liderança indígena Arapiuns Y, Santarém (PA), 15 Jun. 2012).
}

Os mecanismos acionados pela liderança indígena para pressionar o Estado e garantir a permanência no seu espaço recorrem à junção da tríade identidade, território e preservação ambiental. Essa afirmação de identidades diferenciais se dá, assim, em um campo complexo que envolve os enfrentamentos no local, os dispositivos de regulação do Estado, bem como os debates em esferas internacionais - Banco Interamericano de Desenvolvimento (BID), Organização Internacional do Trabalho (OIT) -, sobre como se definem as diferenças que verdadeiramente valem nessa disputa (Hoffman, 2010). O que está em jogo, portanto, na luta pela identidade e pelo reconhecimento é a imposição de percepções e categorias de percepção (Bourdieu, 1989). Em um contexto de disputas territoriais, como no caso da Amazônia, a politização da identidade representa uma forma de afiançar a permanência no lugar e nesse digladio a riqueza cultural aparece como caractere que dota certos grupos de particularidades diferenciais (Assis \& Lages, 2015). A cultura como recurso (Yúdice, 2013) e o recurso à cultura aparecem, portanto, como estratégias de mobilização para fazer frente às dinâmicas expropriatórias que atingem populações camponesas e tradicionais na medida em que o capital avança sobre novos territórios amazônicos. A cultura associa por assim dizer as pessoas à terra, consequentemente, grupos portadores de cultura ganham passaportes para direitos à cidadania; identidades 
étnicas e culturais passam a ser armas que muitos grupos minoritários utilizam para se defenderem contra outros grupos mais fortes (Almeida, 2007).

Essa incessante construção, reconstrução e politização identitária ganha novos contornos quando se dá o enfrentamento entre comunidades tradicionais e novas frentes de expansão econômica, que trazem consigo um renitente processo de mercantilização das terras. Como observado no fragmento de entrevista anteriormente apresentado, a afirmação identitária é significada como resistência à expropriação territorial representada por projetos de exploração econômica, ao mesmo tempo em que o território é apresentado como garantidor da existência cultural sem a qual fenece a capacidade de reprodução do grupo. Aqui o "étnico" deixa de caracterizar primordialmente um processo de "decadência e desestruturação" - como em fricção interétnica (Cardoso Oliveira, 1978) - para designar tanto movimentos de resistência como projetos políticos nos quais as particularidades culturais dos grupos desempenham um papel fundamental (Guedes, 2011). O recurso aos atributos culturais e as reivindicações pelo reconhecimento cultural aparecem, assim, como meios para se alcançar o esvaziamento do domínio ou da privação injusta (Young, 2000: 83). A cultura e seu uso político podem ser vistos, consequentemente, como estratégias de luta para conquista e manutenção dos territórios. Para além de um enfrentamento contra a expropriação material, representada pela usurpação das riquezas naturais, há um embate para manter de pé e fazer perpetuar no lugar e no tempo certas formas diferenciais de se pensar, apropriar e significar o meio ambiente, que, por sua vez, está umbilicalmente conectado às práticas culturais. Como sugerem Bourdieu e Sayad (2006) - quando da análise do impacto da colonização francesa na Argélia -, o empreendimento colonial retirou do camponês argelino mais do que a terra, despojou-o de um bem que não Ihe pode ser magicamente restituído ou atribuído e que ele deve não somente refazer, mas fazer: sua própria cultura.

Na ótica de Spivak (2010), o itinerário do reconhecimento por meio da assimilação do outro pode ser traçado de maneira mais interessante a partir da constituição imperialista do sujeito colonial. A partir da ideia de violência epistêmica, a autora demonstra como a empresa colonial fabricou a negação do outro como sujeito e impediu o florescimento de formas distintas de se conceber o mundo. Pode-se dizer que, no contexto atual, a concepção eurocêntrica de um mundo uno, que se fundou primeiramente na celebração da homogeneidade e na evolução unidirecional, tem sido reelaborada pelo capitalismo equânime, que passa a promover a diversidade, a pluralidade e o multiculturalismo como estratégias capazes de alargar as bases de exploração e ocupação territorial. Não obstante, esteja em jogo o estabelecimento das diferenças que valem em conjugação com a aceitabilidade discursiva da alteridade, as tentativas de silenciamento do outro tem sido uma constante na lógica 
4. Para Guha (1997) mudar o mundo e mantê-lo em seu estado corrente tem sido a função dual da historiografia liberal europeia - mudar o mundo segundo interesses próprios da classe dominante. Dito de outro modo, significa mudar tudo para que tudo permaneça como sempre esteve. de expansão da acumulação capitalista. Sobre esse aspecto, o trecho transcrito a seguir - retirado de entrevista realizada com uma liderança indígena do povo Borari - elucida o confronto entre lógicas distintas, além de iluminar o caráter provinciano das estratégias de desenvolvimento econômico:

\begin{abstract}
A partir do momento que você é uma liderança indígena, que você é um liderança ribeirinha, que você é uma liderança quilombola, a partir do momento que você começa a falar em público e a denunciar as injustiças que estão ocorrendo, a primeira coisa que tu vais arranjar é inimigo, porque esse modelo capitalista ele não aceita a demarcação de terras indígenas, ele não aceita assentamentos, ele não aceita reservas, ele não aceita nada que seja preservação, porque isso impede o tal desenvolvimento que eles dizem, o tal desenvolvimento que é pensado para a Amazônia, mas esse não é um modelo de desenvolvimento que possa ser considerado bom para nós (entrevista com liderança indígena Borari T, Santarém (PA), 11 Jun. 2012).
\end{abstract}

Ontem e hoje esses mecanismos de alargamento da acumulação capitalista cumprem um eficiente papel de turvar nossa compreensão de que a heterogeneidade histórico-estrutural, a copresença de tempos históricos e de fragmentos estruturais de formas de existência social, de variada procedência histórica e geocultural são o principal modo de existência e de movimento de toda sociedade, de toda história (Quijano, 2005: 14). O historicismo europeu ${ }^{4}$ apostou e aposta no tempo histórico como medida de distância cultural que impõe um abismo entre os sujeitos considerados desenvolvidos ou tradicionais, moderno ou arcaicos, civilizados ou bárbaros. É imprescindível desmistificar o eurocentrismo e o globalcentrismo pela evidenciação de seus mais alienantes procedimentos cognitivos, expressos na condição de um provincianismo prático-intelectual que inflige sua hegemonia mundial como instrumento de dominação. Para Chakrabarty (2007), o pensamento europeu apresenta uma relação contraditória com o seu ideário de modernidade política, sendo ao mesmo tempo indispensável e insuficiente para pensar as práticas que constituem distintas formas de vida política e modos históricos espalhados ao redor do mundo. A ruptura com esse paradigma de conhecimento e ação passa pela tarefa exposta pelo autor indiano de provincializar a Europa explorando esse pensamento que se constituiu como patrimônio de todos, tentando renová-lo, modificá-lo a partir de uma reflexão na e para as margens.

Como a produção intelectual é de muitas maneiras cúmplice dos interesses econômicos internacionais (Spivak, 2010), trata-se de localizar desde onde se pensa, em qual direção se pensa, bem como indagar qual a lógica está subjacente a uma dada forma de se conceber o mundo e quais estruturas de poder esse pensamento 
contribui para manter de pé. Para Grosfoguel (2007), a geopolítica do conhecimento nos obriga a localizar a partir de onde se está pensando e nos mostra como ao mudarmos a geografia da razão ou a localização epistemológica desde a qual se pensa, se transforma a maneira de entender o mundo. A descolonização do imaginário e a desuniversalização das formas coloniais do saber aparecem, portanto, como condições de toda transformação democrática radical que venha a ocorrer nessas sociedades (Lander, 2001). Assim, é justo afirmar com Visvanathan (2003) que a epistemologia de um povo é tão central quanto sua participação em qualquer discurso ou prática democrática.

Em uma toada similar, Santos (2003) designa o projeto de uma sociologia das ausências como uma investigação que visa demonstrar que o que não existe é, na verdade, ativamente produzido como não existente, dito de outro modo, como alternativa não credível ao que existe. A produção de não existentes pode, assim, ser vista como um dos modos através dos quais funciona o poder da colonialidade, que se alimenta da retórica da modernidade, por sua vez, autoconstruída como sinônimo de civilização, progresso, ciência e desenvolvimento, que conduz diretamente à liberdade, à democracia, à justiça e aos direitos humanos ${ }^{5}$. É assim que o trio universalista da ciência, dos direitos humanos e da meritocracia desponta como orgulho maior dos defensores da civilização capitalista (Wallesrtein, 2001). Para fazer emergir a ausência, a próxima seção destina-se a demonstrar que, mesmo diante das históricas tentativas de subalternização, as populações da TI Raposa Serra do Sol têm tentado romper com a "narrativa oficial", que costuma silenciar as reivindicações indígenas em nome de uma construção que produz o exótico, homogeneíza e naturaliza práticas de determinados grupos sociais, para, no mesmo movimento, estabelecer e privilegiar formas consideradas como mais desenvolvidas, modernas, civilizadas e cultas.

\section{A luta sub-alterna na Terra Indígena Raposa Serra do Sol: outro dizer-fazer}

No dia 27 de agosto de 2008, as 376 cadeiras do plenário do Supremo Tribunal Federal (STF) estavam ocupadas; ainda de madrugada, a fila para a sessão já estava sendo formada. A monotonia monocromática dos "brancos em longos trajes negros" (Yamada \& Villares, 2010: 144) era quebrada pelo colorido dos trajes de gala usado pelas diversas lideranças indígenas do Brasil. A TV e a Rádio Justiça transmitiam o julgamento ao vivo. Transcorridos os procedimentos introdutórios, os advogados dos autores da Petição 3388/RR, depois os advogados dos réus, apresentaram suas alegações. Pela primeira vez, um indígena fala no STF, Joênia Batista de Carvalho, vestindo a beca, mas com o rosto pintado, começa sua defesa na língua wapichana e continua em português afirmando:

5. Rancière (2006) argumenta sobre a inclinação criminal da democracia europeia e sugere que o totalitarismo e a democracia não são necessariamente opostos. Em sua tese sobre o novo ódio à democracia vigora a ideia de que existe apenas uma boa democracia, aquela que representa a catástrofe da civilização democrática. 


\begin{abstract}
A terra indígena não é só casa para morar, mas o local onde se caça, onde se pesca, onde se caminha e onde os povos indígenas vivem e preservam sua cultura. A terra não é um espaço de agora, mas um espaço para sempre. Queremos viver conforme nossos usos e costumes, conforme nossas tradições, num ambiente de harmonia e respeito com todos (Carvalho, 2008).
\end{abstract}

Embora inédita e dissonante do que usualmente se escuta no plenário do STF, a voz da advogada indígena encontra eco nos mais de 30 anos de lutas para o alcance da demarcação contínua da TI Raposa Serra do Sol. Em verdade, toda história do processo de colonização da bacia do rio Branco, da própria formação do estado de Roraima e, sobretudo, a partir da década de 1970, quando foi dado início ao processo de demarcação, mostra que as populações indígenas daquela região recusaram o lugar de subalternidade que alguns setores da sociedade pretendiam Ihes infligir. Ainda que continuem sendo reiteradas as tentativas de subjugar as etnias da hoje TI Raposa Serra do Sol, Santilli (2001) percebe que o evento da demarcação possibilitou que organizações indígenas - notadamente o Conselho Indigenista de Roraima - empreendessem esforços destinados a incrementar uma articulação política por parte dos índios na esfera estatal, razão pela qual o autor sustenta o caráter reivindicatório e nada apriorístico da demarcação contínua. A despeito dos conflitos internos e do reconhecimento da existência de indígenas contrários à demarcação contínua, o trecho a seguir (excerto de entrevista realizada durante trabalho de campo na TI Raposa Serra do Sol) apresenta os arranjos e as negociações elaboradas por esses sujeitos na tentativa de manter a unidade no transcorrer do processo de luta pelo reconhecimento de seus direitos:

\footnotetext{
Já para não haver nenhuma desavença, as organizações sempre se juntaram para se fortalecer e mostrar para a população que nosso objetivo não era brigar, a gente só queria o nosso direito [...]. Esse processo todo, hoje, foram várias pessoas, várias instituições, todo um aglomerado de pessoas que conseguiram [a demarcação], porque a gente sabe que lutar contra a mídia, contra a política é difícil, contra a visão que eles vão colocando. Mas o movimento aqui, nós somos muito fortalecido. Mesmo tendo indígenas contrários. Quando houve todo esse processo, depois a gente se reuniu com os indígenas que eram contrários à demarcação e a gente conseguiu se entender, para que não houvesse o conflito (entrevista liderança Wapichana K, Boa Vista (RR), 22 Jul. 2012).
}

Repetto (2008) afirma ser problemático posicionar o indígena como sujeito alheio à sua própria história, que, ao ignorar suas interpretações sobre o ambiente externo, enquadra-os como simples receptores de ações indigenistas. Nesse sentido, o frag- 
mento apresentado dá conta do processo de reconstrução das alianças indígenas, bem como o disposto a seguir (retirado de entrevista com uma liderança Wapichana) reflete a implantação de políticas públicas destinadas aos indígenas e ajuda a ilustrar o protagonismo de populações subalternizadas na luta pela consecução de seus direitos:

\begin{abstract}
São muitos anos de discussão, então as comunidades são sabedoras dos direitos delas. Foi uma coisa que nós trabalhamos muito, muito, muito, muito. Conheça os seus direitos, que é uma coisa que eu vejo que o não indígena não vai buscar. Quando a gente debatia assim e o pessoal dizia: "mas vocês são cheios de direitos, vocês querem". A palavra tá dizendo, direito, conquistado, está aí na legislação. Nós indígenas, nós aprendemos, que é tudo pela lei, tudo pelo documento, que é tudo escrito. Nossa palavra, nós falamos, mas se não estiver escrito aí, pra vocês não vale nada. Pergunta pra um indígena, pra ver se ele não sabe quais são os artigos todos. Então, você chega na comunidade vai ver um tuxaua falar da Constituição, ele fala até da OIT. Ele sabe. Às vezes o pessoal se assusta, né? (entrevista liderança Wapichana K, Boa Vista (RR), 22 Jul. 2012).
\end{abstract}

A enunciação sub-alterna que se articula com a organização política tem os méritos de fazer ecoar demandas que de outro modo seriam silenciadas; exemplo disso, é que tão logo foi impetrada ação que questionava a legalidade da demanda indígena, iniciou-se uma forte campanha nacional e internacional em favor da demarcação contínua. No âmbito interno, um dos alvos foi o próprio STF, órgão responsável por proferir a decisão. Assim, ao longo dos quase quatro anos de processo, foram solicitadas audiências com os ministros do STF pelos representantes indígenas, com o intuito de defender a demarcação nos moldes como havia sido realizada. Ao levar em conta a impressão de habitualidade fornecida pelo relato, o trecho abaixo nos permite perceber que os membros das comitivas indígenas mapearam o perfil dos ministros de uma maneira sistemática. O repasse das informações de um grupo a outro antes dos encontros permitiu-lhes identificar os posicionamentos pessoais de alguns ministros em relação ao caso, contribuindo para elaboração de suas estratégias:

[...] a gente queria chamar a atenção do mundo para o julgamento do STF. Da imprensa principalmente, a gente queria chamar a atenção da imprensa, para saber o que ia passar, né? Nós conseguimos atingir nosso objetivo, porque ao mesmo tempo em que a gente estava fazendo essa campanha na Europa, aqui as lideranças estavam em Brasília e as comunidades estavam mobilizadas aqui. Foi uma rede que nós criamos para chamar a atenção. Essa campanha teve como objetivo levar lideranças para conversar com os 
ministros do STF. [...] Cada vez ia uma comitiva falar com os ministros, né? Como é um trabalho coletivo, chegava e dizia, olha, ele é assim, assim, assim. Então, assim, já dava para saber quem era quem, quem eram os ministros mais favoráveis, quem tinha mais resistência. Claro que alguns receberam por mais tempo, assim como [teve] ministro que recebeu a documentação no corredor. E a gente já entendia porque que era aquele recebimento no corredor (entrevista liderança indígena Wapichana K, Boa Vista (RR), 22 Jul. 2012).

Decerto, embora extremamente importantes, não se pode compreender o resultado da demarcação contínua da TI Raposa Serra do Sol unicamente pelas lentes de uma perspectiva reivindicatória e das articulações manejadas pelos povos indígenas. Primeiro porque, no plano político, a demarcação foi um compromisso de campanha do presidente Lula em 2002. A repercussão internacional das lutas por reconhecimento certamente ajudou a formar o convencimento de que seria interessante mostrar para o mundo que o Brasil não era o país "que pior tratava seus índios", retirando da opinião internacional a impressão de que o Brasil era um país bárbaro (Lima, 1995). No entanto e, também por isso, a luta pelo reconhecimento de seus direitos soube se valer do atual e ilusório discurso de respeito às diferenças e, a partir do ingresso na própria ordem multicultural hegemônica, minar e questionar aquilo que revela sua maior incoerência, o argumento que fixa o lugar como local da tradição e do atraso.

Segundo porque, na tentativa de acomodar as pressões que vinha sofrendo com o julgamento, a decisão proferida pretendeu ser um marco regulatório nos casos de demarcação de terras indígenas, "deixando fundadas as bases jurídicas para o contínuo reconhecimento aos povos indígenas das terras que tradicionalmente ocupam" (Brasil, 2008: 760). Fez isso com a anexação de 19 condicionantes à decisão. Embora algumas apenas reafirmem os direitos estabelecidos no art. 231 da Constituição da República, outras, como as que estabelecem regras ao usufruto dos indígenas em relação a seus territórios tradicionais e as que vedam a ampliação de terras já demarcadas, são absolutamente inconstitucionais, contrariando mesmo o dever de consulta às comunidades indígenas previsto na Convenção 169 da OIT. O próprio estabelecimento de condicionantes foi uma completa inovação do STF; elas não existem no ordenamento jurídico nem mesmo como salvaguardas institucionais, como se quis valer crer. O ativismo judicial, que ocorre quando a decisão do juiz tem em vista acelerar ou obstar a mudança social (Garapon, 1986), fica claro quando se percebe ao longo dos votos dos ministros, a pretensão de se estender a decisão da TI Raposa Serra do Sol a outros casos. Sobre essa vontade, o ministro Menezes Direito afirmou: 


\begin{abstract}
A partir da apreciação deste caso pude perceber que os argumentos deduzidos pelas partes são também extensíveis e aplicáveis a outros conflitos que envolvam terras indígenas. A decisão adotada neste caso certamente vai consolidar o entendimento da Suprema Corte sobre o procedimento demarcatório com repercussão também para o futuro. Daí a necessidade de o dispositivo explicitar a natureza do usufruto constitucional e seu alcance (Brasil, 2008: 420).
\end{abstract}

A consequência imediata das condicionantes foi a tentativa da Advocacia-Geral da União (AGU) de fixar como normativa, por meio de sua Portaria 303, de 16 de julho de 2012, que dispõe sobre as salvaguardas institucionais às terras indígenas, aquele entendimento fixado pelo STF na Petição 3388/RR. O objetivo seria atrelar a interpretação das unidades da AGU aos termos das condicionantes postas pelo STF no caso da TI Raposa Serra do Sol.

Após a decisão, foram opostos embargos de declaração para esclarecer a extensão da aplicabilidade das condicionantes. No dia 23 de outubro de 2013, o Supremo voltou atrás e decidiu que sua validade seria apenas para a TI Raposa Serra do Sol, não tendo, portanto, efeito vinculante. Sobre a Portaria 303, sua orientação ainda permanece em aberto, logo após a decisão, o advogado-geral da União reafirmou a necessidade de observância da jurisprudência do Supremo no caso da Raposa Serra do Sol, no entanto, no dia seguinte, (24 de outubro de 2013) divulgou nota informando que a AGU estudaria a implantação da Portaria (Brasil, 2013).

Após seis anos do reconhecimento da legalidade da demarcação contínua da Terra Indígena Raposa Serra do Sol, percebe-se que o STF tem acionado aquelas condicionantes para decidir os casos de demarcação posteriores à Raposa, como os das Terras Indígenas Porquinhos dos Canelas-Apãnjekra, localizada no Maranhão e Guyraroka, pertencente à etnia Guarani Kaiowá, situada no Mato Grosso do Sul. Ao falar sobre a aplicabilidade das normas constitucionais, Lassale (2001) sustenta que esta estaria dependente também de um ambiente disposto a receber determinada decisão. Nesse sentido, a despeito dos tribunais serem compreendidos como a instância garantidora dos direitos das minorias, os casos concretos não têm validado essa representação (Carrió, 1986). Ao contrário, sua atuação contramajoritária restaria facilitada quando não mais existissem maiorias adversárias na arena política.

A demarcação da TI Raposa Serra do Sol sinaliza que, a despeito das tentativas de subalternização operadas pelo STF, a partir do acionamento de um instrumental jurídico destinado a acomodar interesses da dita maioria e arrefecer os impactos de 
futuras demandas territoriais de grupos étnicos, as populações indígenas lograram resguardar seus direitos constitucionais e fizeram ressoar as vozes dissonantes que resistem e enunciam sua permanência nesse campo de disputas.

Abstract: To reflect on the continuity of subordination processes and expropriation of the traditional populations the article will be anchored in the approaches the paradigm modernity-coloniality. It will try to connect the theoretical problem thus constructed with the empirical knowledge of territorial changes occurred in the Amazon region, a move that will submit to question certain aspects of social reality and to turn the spiral connecting conceptual abstraction and reality. To do it the analysis undertaken here makes use of two field studies conducted in different Amazonian spaces; the first carried out in the western region of Pará, which over the last decade has been the locus of intense conflict between the fronts of economic expansion and traditional populations. The second held in the Raposa Serra do Sol, which is a paradigmatic case whereupon the judgment put in opposition rationalities different and modes of use, significance and appropriation of territory.

Keywords: coloniality-modernity, development, subordination processes, territorial expropriation, resistance.

\section{Referências}

ALMEIDA, M. Narrativas agrárias e a morte do campesinato. Ruris, v. 1, n. 2, p. 157176, 2007.

ASSIS, W. F. T.; LAGES, A. S. Há diferenças que fazem diferença? Lutas identitárias e conflitos ambientais nas dinâmicas de expansão capitalista da Amazônia. Ciências Sociais Unisinos, v. 51, p. 61-71, 2015.

BOURDIEU, P. O poder simbólico. Rio de Janeiro; Lisboa: Bertrand Brasil; Difel, 1989.

BOURDIEU, P.; SAYAD, A. A dominação colonial e o saber cultural. Revista de Sociologia Política, n. 26, p. 41-60, 2006.

BOURDIEU, Pierre ; WACQUANT, Loïc. Sobre as Artimanhas da Razão Imperialista. Estudos afro-asiáticos, v. 24, n. 1, p.15-33, 2002.

BRASIL. Supremo Tribunal Federal. Recurso Ordinário em Mandado de Segurança n. 29.542. 2014a. Disponível em: <http://redir.stf.jus.br/paginadorpub/paginador. jsp?docTP=TP\&docID=6937880>. Acesso em: 25 Mar. 2015.

—. Recurso Ordinário em Mandado de Segurança.n. 29.087. 2014b. Disponível em: <http://redir.stf.jus.br/paginadorpub/paginador.jsp?docTP=TP\&doclD= 7218303>. Acesso em: 25 Mar. 2015. 
- Regimento Interno [atualizado até dezembro de 2013] - consolidado e atualizado até maio de 2002 por Eugênia Vitória Ribas. Brasília: STF, 2013.

—. Petição n.o 3 388/RR. Relator ministro Carlos Ayres Britto. Brasília: TSF, 2008. Disponível em: <http://www.stf.jus.br/portal/principal/principal.asp>. Acesso em: 11 Mar. 2010.

CARDOSO DE OLIVEIRA, R. Problemas e hipóteses relativos à fricção interétnica. América Latina, v. 6, n. 3, p. 33-45, 1978.

CARRIÓ, Genaro R. Notas sobre derecho y lenguaje. Buenos Aires: Abeledo-Perrot, 1986.

CARVALHO, Joênia Batista. Sustentação oral proferida por ocasião da votação da Petição 3 388, em 27 de agosto de 2008. Disponível em: <http://www.youtube.com/ watch?v=aEcROgWHjmk>. Acesso em: 22 Jan. 2012.

CASTRO-GÓMEZ, Santiago. Ciencias sociales, violencia epistémica y el problema de la invención del otro. In: LANDER, Edgardo (Comp.). La colonialidad del saber: eurocentrismo y ciencias sociales. Perspectivas Latinoamericanas. Buenos Aires: Clacso, 2000.

CHAKRABARTY, Dipesh. Provincializing Europe. Post- colonial thought and historical difference. Nova Jersey: Princeton University Press, 2000.

DA ROS, Luciano. Tribunais como árbitros ou como instrumentos de oposição: uma tipologia a partir dos estudos recentes sobre judicialização da política com aplicação ao caso brasileiro contemporâneo. Direito, Estado e Sociedade, n. 31, 2007.

DIRLIK, Arif. The postcolonial aura: third world criticism in the age of global capitalism. Boulder: Westview Press, 1997.

DUSSEL, Enrique. Europa, modernidad y eurocentrismo. In: LANDER, Edgardo (Comp.). La colonialidad del saber: eurocentrismo y ciencias sociales. Perspectivas Latinoamericanas. Buenos Aires: Clacso, 2000.

ESCOBAR, Arturo. El Lugar de la naturaleza y la naturaleza del lugar: globalización o postdesarrollo? In: LADER, E. (Org.). La colonialidad del saber: eurocentrismo y ciencias sociales, perspectivas latinoamericanas, p. 115-152. La Habana: Editorial de Ciencias Sociales, 2005.

—. Mundos y conocimientod de otro modo: el programa de investigación de modernidad/colonialidad latinoamericano. Tabula Rasa, n. 1, Ene./Dic. 2003. 
FAIRCLOUGH, Norman. Discurso e mudança social. Brasilia: EdUnB, 2001.

GARAPON, Antoine. O juiz e a democracia: o guardião das promesas. 2. ed. Rio de Janeiro: Revan, 1986.

GARCÉS, Fernando. Las políticas del conocimiento y la colonialidad lingüística y epistémica. In: CASTRO-GÓMEZ, S.; GROSFOGUEL, R. El giro decolonial. Reflexiones para una diversidad epistémica más allá del capitalismo global. Bogotá: Universidad Javeriana, 2007.

GONZALEZ-CASANOVA, P. Colonialismo interno: uma redefinição. In: BORON, Atílio et alii. La teoría marxista hoy: problemas y perspectivas. Buenos Aires: Clacso, 2006.

GROSFOGUEL, Ramón. Descolonizando los universalismos occidentales: el pluri-versalismo transmoderno decolonial desde Aimé Césaire hasta los zapatistas. In: CASTRO-GÓMEZ, S.; GROSFOGUEL, R. El giro decolonial. Reflexiones para una diversidad epistémica más allá del capitalismo global. Bogotá: Universidad Javeriana, 2007.

- La descolonización de la economía política y los estudios postcoloniales: transmodernidad, pensamiento fronterizo y colonialidad global. Tabula Rasa, n. 4, p. 17-48, Ene./Jun. 2006.

GUEDES, A. D. A fronteira e as fronteiras entre camponeses, indígenas e comunidades tradicionais: relendo José de Souza Martins. XVII Semana PUR, Anais da XVII Semana PUR, 2011.

GUHA, Ranajit. Dominance without hegemony: history and power in colonial India. Cambridge: Cambridge University Press, 1997.

HALE, Charles. Does multiculturalism menace? Governance, cultural rights and the politics of identity in Guatemala. Journal of Latin American Studies, v. 34, p. 485524, 2002.

HOFFMAN, M. B. Mapeamentos participativos e atores transnacionais: a formação de identidades políticas para além do Estado e dos grupos étnicos. In: ACSELRAD, Henri (Org.). Cartografia social e dinâmicas territoriais. Marcos para o debate. Rio de Janeiro: Ippur-UFRJ, 2010.

KHATIBI Abdelkebir. Maghreb plural. In: MIGNOLO, Walter (Comp.). Capitalismo y geopolítica del conocimiento: el eurocentrismo y la filosofía de la liberación en el debate intelectual contemporáneo. Buenos Aires: Ediciones del Signo, 2001. 
—. Un étranger professionnel. Études Françaises, v. 33, n.1, p. 123-126, 1997.

LANDER, Edgardo. Ciencias sociales: saberes coloniales y eurocéntricos. In: LANDER, E. (Comp.). La colonialidad del saber: eurocentrismo y ciencias sociales. Perspectivas Latinoamericanas. Buenos Aires: Clacso, 2001.

LASSALLE, Ferdinand. A essência da constituição. Rio de Janeiro: Lumem Juris, 2001.

LATOUR, Bruno. Jamais fomos modernos: ensaio de antropologia simétrica. Rio de Janeiro: Editora 34, 1994.

LIMA, Antonio Carlos de Souza. Um olhar sobre a presença das populações nativas na invenção do Brasil. In: SILVA, Aracy Lopez da; GRUPIONI, Luiz Donisetti Benzi (Orgs.). A questão indígena na sala de aula: novos subsídios para professores de 1 은 e 2o graus. Brasília: MEC, 1995.

MAINGUENEAU, Dominique. Novas tendências em análise do discurso. Campinas: Editora Unicamp, 1997.

MALDONADO-TORRES, Nelson. A topologia do Ser e a geopolítica do conhecimento. Modernidade, império e colonialidade. In: SANTOS, Boaventura de Sousa; MENESES, Maria Paula. Epistemologias do Sul. São Paulo: Cortez, 2010.

MALDONADO-TORRES, Nelson. Sobre la colonialidad del ser, contribuciones al desarrollo de un concepto. In: CASTRO-GOMEZ, Santiago; GOSFROGUEL, Ramón (Comps.). El giro decolonial. Reflexiones para una diversidad epistémica más allá del capitalismo global. Bogotá: Universidad Javeriana-Instituto Pensar; Universidad Central-lesco; Siglo del Hombre, 2007.

MASSEY, Doreen. Um Sentido Global do Lugar. In: ARANTES, Antonio Augusto. O espaço da diferença. São Paulo: Papirus, 2000.

MIGNOLO, Walter. Histórias locais / projetos globais: colonialidade, saberes subalternos e pensamento liminar. Belo Horizonte: Editora UFMG, 2003.

- Introdución. In: MIGNOLO, W. Capitalismo y geopolítica del conocimiento: eurocentrismo, y filosofía de la liberación en el debate intelectual contemporáneo. Buenos Aires: Editorial Signo, 2001.

ORLANDI, Eni Pulcinelli. Discurso e leitura. São Paulo: Cortez, 1988.

QUIJANO, Aníbal. Don Quijote y los molinos de viento en América Latina. Revista Electrónica de Estudios Latinoamericanos, Área Sociología Histórica. Instituto de Investigaciones Gino Germani, Facultad de Ciencias Sociales, Universidad de Buenos Aires, v. 4, n. 14, Ene.-Mar. 2005. 
- Los movimientos campesinos contemporáneos en América Latina. OSAL, Debates Teoricos, Sep. 2000a.

- Colonialidad del poder y clasificacion social. Journal of World Systems-Research, v. 11, n. 2, p.342-386, 2000b.

- Colonialidad del poder, cultura y conocimiento en América Latina. Anuário Mariateguiano, v. 9, n. 9, 1997.

RANCIÈRE, Jacques. Hatred of democracy. London: Verso, 2006.

REPETTO, Maxim. Movimentos indígenas e conflitos territoriais no estado de Roraima. Boa vista: Editora UFRR, 2008.

SANTILLI, Paulo. Pemongon Patá: território Macuxi, rotas de conflito. São Paulo: Editora Unesp, 2001.

SANTOS, Boaventura de Sousa. Para uma sociologia das ausências e uma sociologia das emergências. In: SANTOS, Boaventura de Sousa (Org.). Conhecimento prudente para uma vida decente: um discurso sobre ciências revisitado, p. 777-821. São Paulo: Cortez, 2003.

SPIVAK, A. Pode o subalterno falar? Belo Horizonte: Editora UFMG, 2010.

STENGERS, Isabelle; PIGNARRE, Philippe. La sorcellerie capitaliste: pratiques de désenvoûtement. Paris: La Découverte, 2005.

VISVANATHAN, Shiv. Convite para uma guerra da ciência. In: SANTOS, Boaventura de Sousa (Org.). Conhecimento prudente para uma vida decente, p. 757-776. São Paulo: Cortez, 2003.

WALLERSTEIN, Immanuel. Capitalismo histórico \& civilização capitalista. Rio de Janeiro: Contraponto, 2001.

— The capitalist world-economy. Cambridge; Paris: Cambridge University Press; Éditions de la Maison des Sciences de l'Homme, 1979.

WALSH, Catherine. Interculturalidad y colonialidad del poder. Un pensamiento y posicionamiento "otro" desde la diferencia colonial. In: WALSH, C.; LINERA, A. G.; MIGNOLO, W. Interculturalidad, descolonización del estado y del conocimiento, p. 21-70. Buenos Aires: Del Signo, 2007.

WALSH, Catherine et alii. Indisciplinar las ciências sociales, geopolitica del conocimiento y colonialidad del poder. Perspectivas desde lo Andino. Quito: Abyala, 2002. 
YAMADA, Érika M.; VILLARES, Luis Fernando. Julgamento da Terra Indígena Raposa Serra Do Sol: todo dia era dia de índio. Revista de Direito GV, n. 6, p. 143-158, Jan./ Jun. 2010.

YOUNG, I. M. Inclusion and democracy. New York: Oxford University Pres, 2000.

YÚDICE, G. A conveniência da cultura: usos da cultura na era global. Belo Horizonte: Editora UFMG, 2013. 